\title{
Economic impacts of care by high-volume providers for non-curative esophagogastric cancer: a population-based analysis
}

\author{
Julie Hallet ${ }^{1,2,3,4} \cdot$ Nicole J. Look Hong ${ }^{1,2,3,4} \cdot$ Victoria Zuk $^{3} \cdot$ Laura E. Davis $^{3} \cdot$ Vaibhav Gupta $^{2} \cdot$ Craig C. Earle $^{3,5}$. \\ Nicole Mittmann ${ }^{3} \cdot$ Natalie G. Coburn ${ }^{1,2,3,4}$
}

Received: 13 November 2019 / Accepted: 6 December 2019 / Published online: 13 December 2019

(c) The International Gastric Cancer Association and The Japanese Gastric Cancer Association 2019

\begin{abstract}
Background Esophagogastric cancer (EGC) is one of the deadliest and costliest malignancies to treat. Care by high-volume providers can provide better outcomes for patients with EGC. Cost implications of volume-based cancer care are unclear. We examined the cost-effectiveness of care by high-volume medical oncology providers for non-curative management of EGC. Methods We conducted a population-based cohort study of non-curative EGC over 2005-2017 by linking administrative datasets. High-volume was defined as $\geq 11$ patients/provider/year. Healthcare costs (\$USD/patient/month-survived) were computed from diagnosis to death or end of follow-up from the perspective of the healthcare system. Multivariable quantile regression examined the association between care by high-volume providers and costs. Sensitivity analyses were conducted by varying costing horizons and high-volume definitions.

Results Among 7011 non-curative EGC patients, median overall survival was superior with care by high-volume providers with 7.0 (IQR 3.3-13.3) compared to 5.9 (IQR 2.6-12.1) months $(p<0.001)$ for low-volume providers. Median costs/patient/ month-lived were lower for high-volume providers ( $\$ 5518$ vs. $\$ 5911 ; p<0.001$ ), owing to lower inpatient acute care costs, despite higher medication-associated and radiotherapy costs. Care by high-volume providers was independently associated with a reduction of $\$ 599$ per patient/month-lived (95\% confidence interval - 966 to - 331) compared to low-volume providers. The incremental cost-effectiveness ratio was -393 . Care by high-volume providers remained the dominant strategy when varying the costing horizon and the high-volume definition.

Conclusion Care by high-volume providers for non-curative EGC is associated with superior survival and lower healthcare costs, indicating a dominant strategy that may provide an opportunity to improve cost-effectiveness of care delivery.
\end{abstract}

Keywords Outcomes $\cdot$ Costs $\cdot$ Cancer $\cdot$ Volume $\cdot$ Esophageal $\cdot$ Gastric

\section{Introduction}

Electronic supplementary material The online version of this article (https://doi.org/10.1007/s10120-019-01031-w) contains supplementary material, which is available to authorized users.

Julie Hallet

Julie.hallet@sunnybrook.ca

1 Division of General Surgery, Odette Cancer Centre, Sunnybrook Health Sciences Centre, 2075, Bayview Avenue, T2-063, Toronto, ON M4N 3M5, Canada

2 Department of Surgery, University of Toronto, Toronto, ON, Canada

3 Sunnybrook Research Institute, Toronto, ON, Canada

4 ICES, Toronto, ON, Canada

5 Department of Medicine, University of Toronto, Toronto, ON, Canada
Cancer care is increasingly complex and there can be variation in patterns of care and outcomes across institutions and providers. A growing number of studies have examined the relationship between clinical volume and outcomes in surgical cancer care and have influenced health policy toward provision of care by high-volume providers [1-3]. Whether clinical volume also plays a role in the delivery of medical cancer care is less clear and the need for such information has been highlighted [4]. Recent data indicated improved survival for solid malignancies with care by high-volume medical oncologists [5-7].

As healthcare costs increase, it is important to better understand how the organization and provision of care relate to both patient outcomes and healthcare expenses. The 
relationships between clinical volumes, cancer outcomes, and cost remain largely unknown [8]. With current cost and resource constraints, it is ever more critical to consider costs in the development of health policy. However, data on the effect of specialization or volume on costs in cancer care is scarce [9].

Esophagogastric cancer (EGC) is both highly fatal and one of the most expensive cancers to treat on a per-patient basis [10-13]. Care by high-volume providers has recently been independently associated with superior overall survival for EGC patients (hazard ratio-HR 0.89; 95\% confidence interval-95\%CI 0.84-0.93) [6]. However, specialized care by high-volume providers is also associated with increased use of therapy and may be more resource-intensive and costly; the economic impact of such care is unknown.

Thus, we conducted a population-based costing analysis to examine the cost-effectiveness of care by high-volume providers compared to low-volume providers for the noncurative management of EGC.

\section{Methods}

\section{Study design and data sources}

Using linked administrative databases stored at ICES in Ontario, Canada, we conducted a population-based analysis to examine the impact of provider-volume and outcomes on cost, from the healthcare system perspective, over the patient's lifetime following EGC diagnosis. The Ontario population benefits from universally accessible and publicly funded health care through Ontario Health Insurance Plan (OHIP) [14].

The study was approved by the Sunnybrook Health Sciences Centre Research Ethics Board. It was conducted and reported following the REporting of studies Conducted using Observational Routinely collected Data (RECORD) statement and the ISPOR Consolidated Health Economic Evaluation Reporting Standards (CHEERS) [15, 16].

We used population-based healthcare and administrative registries in Ontario as previously been reported and detailed in Supplementary Table 1 [17, 18]. The datasets were linked using unique Identification Key Number (IKN) for each patient.

\section{Study population and cohort}

This study was conducted in all patients with a new diagnosis of esophageal or gastric adenocarcinoma or squamouscell carcinoma from January 1st, 2005 to March 31st, 2017 identified who did not undergo curative-intent therapy and $\operatorname{had} \geq 1$ encounter with medical oncology, using a strategy previously described (Supplementary Table 2) [6].

\section{Exposure}

The exposure of interest was care by a high-volume medical oncology provider, defined as the 4th and 5th quintile of provider volume and set at $\geq 11$ patients per provider per year, as previously described (Supplementary Table 3) [6].

\section{Outcomes measures}

We used a bottom-up approach to determine patient-level costs. Costs were computed using: (1) disaggregated general healthcare costs, and cancer-specific costing for (2) medication-associated costs (including systemic therapy) and (3) radiotherapy costs [19-21]. Median cost per patient per month-survived were computed as adjusted $2018 \mathrm{CAD}$ and converted to 2018 USD. A conversion of 1 Canadian dollar to 0.72 US dollars was applied, as per the Bank of Canada's rate in 2018. Median costs were analyzed to avoid skewing the measure of central tendency with outliers.

For general healthcare costs, person-level costs were generated using resources for inpatient acute care, ambulatory care, emergency services, prescription drugs, physician claims, inpatient rehabilitation, complex continuing care and long-term care, home care services, admissions to mental health beds, and the assisted device program, for all patients seen by medical oncology providers. For hospital-based encounters, costs are calculated by multiplying resource intensity weight (RIW) for the specific encounter by an annual cost-per-weighted-case to generate the total cost for an encounter [22]. RIWs are annual numerical index values calculated based on the relative costs of treatments for specific patient demographics. For longer-term episodes of care, such as complex continuing care, costs were determined by weighted-days. For claims/visit-based encounters, costs were determined at utilization.

Medication-associated costs were determined using drug-specific patient visit and cost information [23]. Radiotherapy costs encompassed all costs for treatment, planning, and operational. Overhead costs that cannot be attributed to a specific patient or visit, such as equipment and medical physicist costs, were estimated separately to get a per-visit cost.

Survival was measured from date of diagnosis to the date of death according to the RPDB, with patients censored at the date of last contact or end of study date.

\section{Covariates}

Age and sex were obtained from the RPDB. Rural living was determined with postal code of residence [24]. Income quintile was assessed with an ecologic measure based on the 
median income of a patient's postal code of residence using national census data $[25,26]$. The comorbidity burden was measured using the Elixhauser comorbidity index with a 2-year look-back window and dichotomized with a cut-off of 4 for high comorbidity burden [27, 28]. Cancer type was dichotomized as esophageal or gastric. Receipt of chemotherapy was defined by identifying patients with at least two chemotherapy infusions billed from the date of diagnosis to end of follow-up [29-31].

\section{Statistical analysis}

Categorical variables were described as absolute number $(n)$ and proportion (\%) and continuous variables as median with inter-quartile range (IQR). Comparison was undertaken with Chi square test for categorical variables, and the Kruskal-Wallis test for continuous variables. Median survival with $95 \%$ confidence interval $(95 \% \mathrm{CI})$ was computed using Kaplan-Meier methods and compared between groups with the log-rank test [32].

To examine potential drivers of the cost difference between groups, we computed the absolute difference in total cost per patient per month-survived between high and low-volume providers groups, for each cost-category. We computed incremental cost effectiveness ratio (ICER), by dividing the difference in median costs per patient per month-survived by the difference in median survival between high and low-volume providers groups.

Multivariable regression models were constructed to assess the association between care by high-volume provider and overall median cost per patient per month-survived. Relevant demographic and clinical characteristics were identified a priori as potential confounders of the relationship between provider-volume and outcomes. The variables were selected based on clinical relevance and existing literature [33]: age (categorical), sex, comorbidity burden, income, rural living, time period of diagnosis (2005-2010 vs. 2011-2017), and type of cancer (esophageal vs. gastric). Quantile regression of the median cost per patient per month-survived was used and results reported as effect estimate with $95 \%$ confidence interval $(95 \% \mathrm{CI})$.

\section{Sensitivity analysis}

We conducted sensitivity analyses to assess the robustness of the results. First, we varied the time horizon to capture costs to ascertain whether differences in costs and cost-effectiveness varied with increasing time from diagnosis: costs were computed for the first 3, 6, and 9 months following date of diagnosis. The number of patients included in each analysis varied depending on length of follow-up. Second, we varied the definition of high-volume providers: costs and median survival were computed using the second $(\geq 6)$, third $(\geq 8)$, and fifth $(\geq 15)$ quintiles of provider-volume [6].

Statistical significance was set at $p \leq 0.05$. All analyses were conducted using SAS Enterprise Guide 6.1 (SAS Institute, Cary, NC, USA).

\section{Results}

A total of 7011 patients were identified with a new diagnosis of EGC, who did not receive curative-intent surgery or chemoradiation therapy and had a medical oncology
Fig. 1 Flow diagram of cohort creation

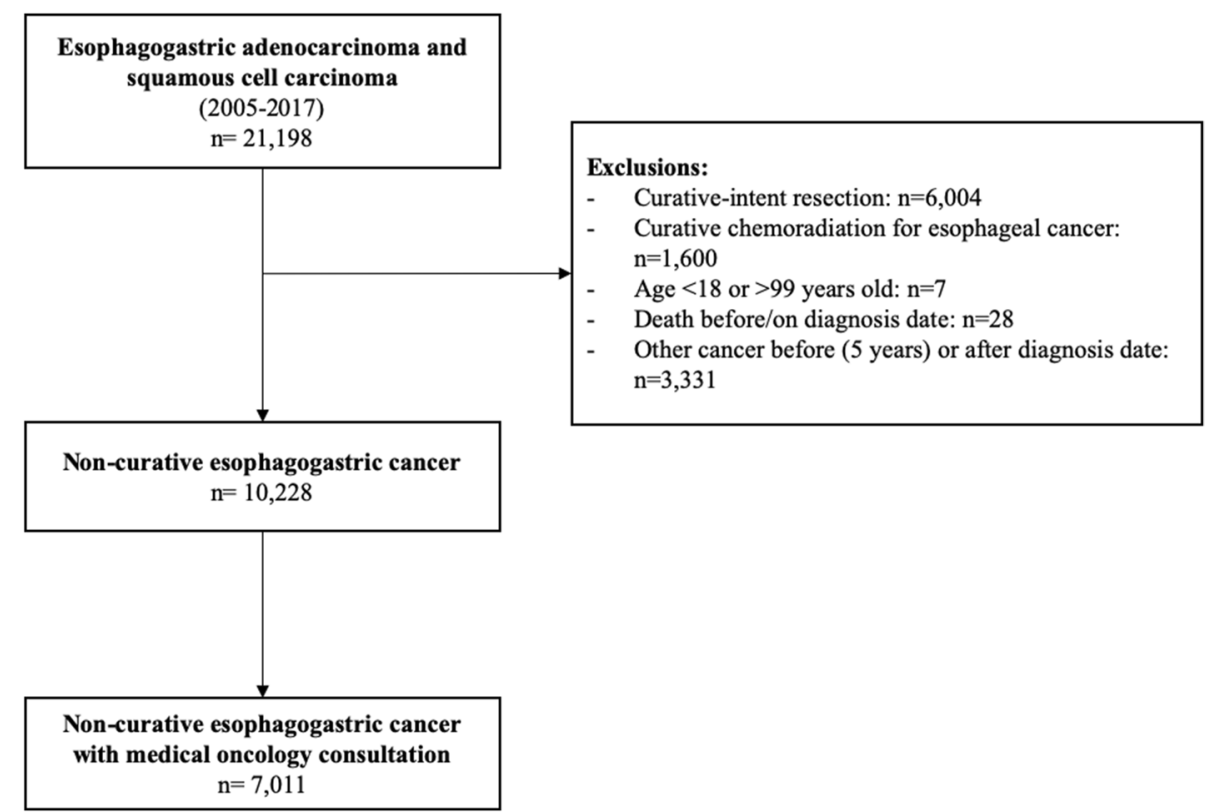


consultation (Fig. 1). Characteristics of included patients are presented in Table 1. Median follow-up was 6.3 (IQR 1.9-11.9) months. High-volume providers ( $\geq 11$ patients/ provider/year) cared for 2,518 (35.9\%) patients. Patients cared for by high-volume providers were more likely to receive chemotherapy, with $50.8 \%$ compared to $44.9 \%$ for low-volume providers $(p<0.001)$. Median survival was 7.0 (IQR 3.3-13.3) months for high-volume providers compared to 5.9 (IQR 2.6-12.1) months for low-volume providers $(p<0.001)$.

Median costs/patient/month-survived are detailed in Table 2, for each cost category. Total median cost/patient/ month-survived was lower for high-volume providers than for low-volume providers, with 7,456 USD (IQR 4325-12,564) compared to 7987 USD (IQR 4435-15,100). The ICER for high-volume providers in the main analysis was -393 , indicating that for each patient cared for by a high-volume provider, there was a cost-saving of 393 USD per month-survived. This showed a dominant strategy. The examination of absolute differences in total costs/patient/ month-survived by cost category is presented in Fig. 2. While cancer treatment costs related to radiotherapy and

Table 1 Characteristics of patients with non-curative management of esophagogastric cancer, stratified by receipt of care by low and highvolume providers

\begin{tabular}{|c|c|c|c|}
\hline Variable & $\begin{array}{l}\text { Low-volume } \\
\text { providers } \\
(<11 \text { patients/ } \\
\text { year) } n=4493\end{array}$ & $\begin{array}{l}\text { High-volume } \\
\text { providers } \\
\text { ( } \geq 11 \text { patients/ } \\
\text { year) } n=2518\end{array}$ & $p$-value \\
\hline \multicolumn{4}{|l|}{ Cancer type } \\
\hline Esophageal & $1423(31.7 \%)$ & $997(39.6 \%)$ & \multirow[t]{2}{*}{$<0.001$} \\
\hline Gastric & $3070(68.3 \%)$ & $1521(60.4 \%)$ & \\
\hline \multicolumn{4}{|l|}{ Age (years old) } \\
\hline$\leq 60$ & $1187(26.4 \%)$ & $794(31.5 \%)$ & \multirow[t]{4}{*}{$<0.001$} \\
\hline $61-70$ & $1156(25.7 \%)$ & $699(27.8 \%)$ & \\
\hline $71-80$ & $1213(27.0 \%)$ & $643(25.5 \%)$ & \\
\hline$\geq 81$ & $937(20.9 \%)$ & $382(15.2 \%)$ & \\
\hline Female sex & $1496(33.3 \%)$ & $689(27.4 \%)$ & $<0.001$ \\
\hline $\begin{array}{l}\text { High comorbidity burden } \\
\text { (Elixhauser index } \geq 4)\end{array}$ & $480(10.7 \%)$ & $246(9.8 \%)$ & 0.23 \\
\hline Rural residence & $592(13.2 \%)$ & $326(12.9 \%)$ & 0.89 \\
\hline \multicolumn{4}{|l|}{ Income quintile } \\
\hline 1st (lowest) & $946(21.1 \%)$ & $509(20.2 \%)$ & \multirow[t]{5}{*}{0.16} \\
\hline $2^{\text {nd }}$ & $993(22.1 \%)$ & $521(20.7 \%)$ & \\
\hline $3^{\text {rd }}$ & $908(20.2 \%)$ & $526(20.9 \%)$ & \\
\hline $4^{\text {th }}$ & $869(19.3 \%)$ & $499(19.8 \%)$ & \\
\hline 5th (highest) & $777(17.3 \%)$ & $463(18.4 \%)$ & \\
\hline \multicolumn{4}{|l|}{ Time period of diagnosis } \\
\hline 2005-2011 & $2190(48.7 \%)$ & $1113(44.2 \%)$ & \multirow[t]{2}{*}{$<0.001$} \\
\hline 2012-2017 & $2303(51.3 \%)$ & $1405(55.8 \%)$ & \\
\hline
\end{tabular}

Values are $n(\%)$ representing column percentages medications were higher for high-volume providers, lower inpatient acute care costs drove the overall cost savings.

After adjusting for age, sex, comorbidity burden, income quintile, rural residence, cancer type, and time period of diagnosis, care by high-volume providers was still associated with lower costs compared to low-volume providers (effect estimate $-599 ; 95 \% \mathrm{CI}-866$ to -331 ).

With regards to sensitivity analyses, changes in time horizon modified the absolute difference in median costs per patient per month-survived between high and lowvolume providers, but not its direction, with -716 USD for 3-month, -642 USD for 6-month, and - 543 USD for 9 -month time horizons. The incremental costs and survival benefits when varying the definition of high-volume providers are depicted in Fig. 3. Care by high-volume providers remained the dominant strategy for all definitions. The cutoff of $\geq 11$ patients/provider/year (4th quintile) presented the largest gain in survival for the reduction in cost.

\section{Discussion}

In this population-based economic analysis, we examined the costs of care by high-volume ( $\geq 11$ patients/provider/ year) providers which led to both longer survival and lower healthcare costs, with an ICER of - 393 indicating a dominant strategy, for non-curative EGC. It was independently associated with reduction in median cost per patient per month-survived. The direction of the cost difference persisted with changes in time horizons and the finding of dominant strategy was robust to variations in high volume definition.

Higher clinical volume has recently been associated with superior survival for medical oncology care [34-38]. From policy and system perspectives, it is important to consider healthcare costs along with outcomes when looking at feasibility of changes in care organization $[9,11]$. Prior economic analyses of EGC care focused on comparing therapeutic regimens [11, 39-42]. Analyses examining healthcare costs in relation to clinical volume have been limited to surgical care, single care episodes, in-hospital costs, and short timehorizon of maximum 12 months [12, 33, 43-45]. The most comprehensive analysis of the economics of medical oncology volume-based management did not include community, ambulatory, or home-based care, was limited in time horizon, included patients treated with curative and non-curative intents, and did not relate costs to patient outcomes [46]. Herein, we leveraged unique comprehensive and complete healthcare data for an entire population under a single-payer system to analyze the cost-effectiveness of provider-volume in medical cancer care for non-curative EGC.

Despite higher therapy costs for high-volume providers, the lower use of inpatient services combined with survival 
Table 2 Median costs/patient/ month-survived for noncurative esophagogastric cancer, stratified by receipt of care by low and high-volume providers

\begin{tabular}{lccc}
\hline Cost category & $\begin{array}{l}\text { Low-volume providers } \\
(<11 \text { patients/year }) \\
\text { Median cost (IQR)-USD }\end{array}$ & $\begin{array}{l}\text { High-volume providers } \\
(\geq 11 \text { patients/year }) \\
\text { Median cost (IQR)-USD }\end{array}$ & $p$ value \\
\hline Radiotherapy costs & $36(0-514)$ & $63(0-612)$ & $<0.001$ \\
Medication-associated costs & $47(5-304)$ & $85(14-486)$ & $<0.001$ \\
General healthcare costs & & & \\
Outpatient care & $270(85-592)$ & $283(111-547)$ & 0.21 \\
Ambulatory surgery & $47(0-138)$ & $63(0-153)$ & $<0.001$ \\
Emergency department & $106(102-252)$ & $108(30-222)$ & 0.43 \\
Dialysis costs & $0(0-0)$ & $0(0-0)$ & - \\
Outpatient cancer care* & $91(0-728)$ & $199(0-777)$ & $<0.001$ \\
Inpatient care & $2089(646-7849)$ & $0(0-0)$ & $<0.001$ \\
Rehabilitation & $0(0-0)$ & $0(0-0)$ & - \\
Complex continuing care & $0(0-0)$ & $0(0-0)$ & - \\
Long-term care & $0(0-0)$ & $325(95-668)$ & $<0.001$ \\
Home care services & $283(46-637)$ & $0(0-0)$ & 0.93 \\
Inpatient mental health & $0(0-0)$ & $732(475-1192)$ & 0.001 \\
Physician billings* & $780(467-1387)$ & $4429(2484-8028)$ & $<0.001$ \\
Total-general healthcare & $5114(2648-10,447)$ & $5518(3201-9297)$ & $<0.001$ \\
Total costs & $5910(3282-11,174)$ & & \\
\hline
\end{tabular}

$I Q R$ Inter-quartile range, USD US dollars

*Excluding radiotherapy visits (included in radiotherapy costs)

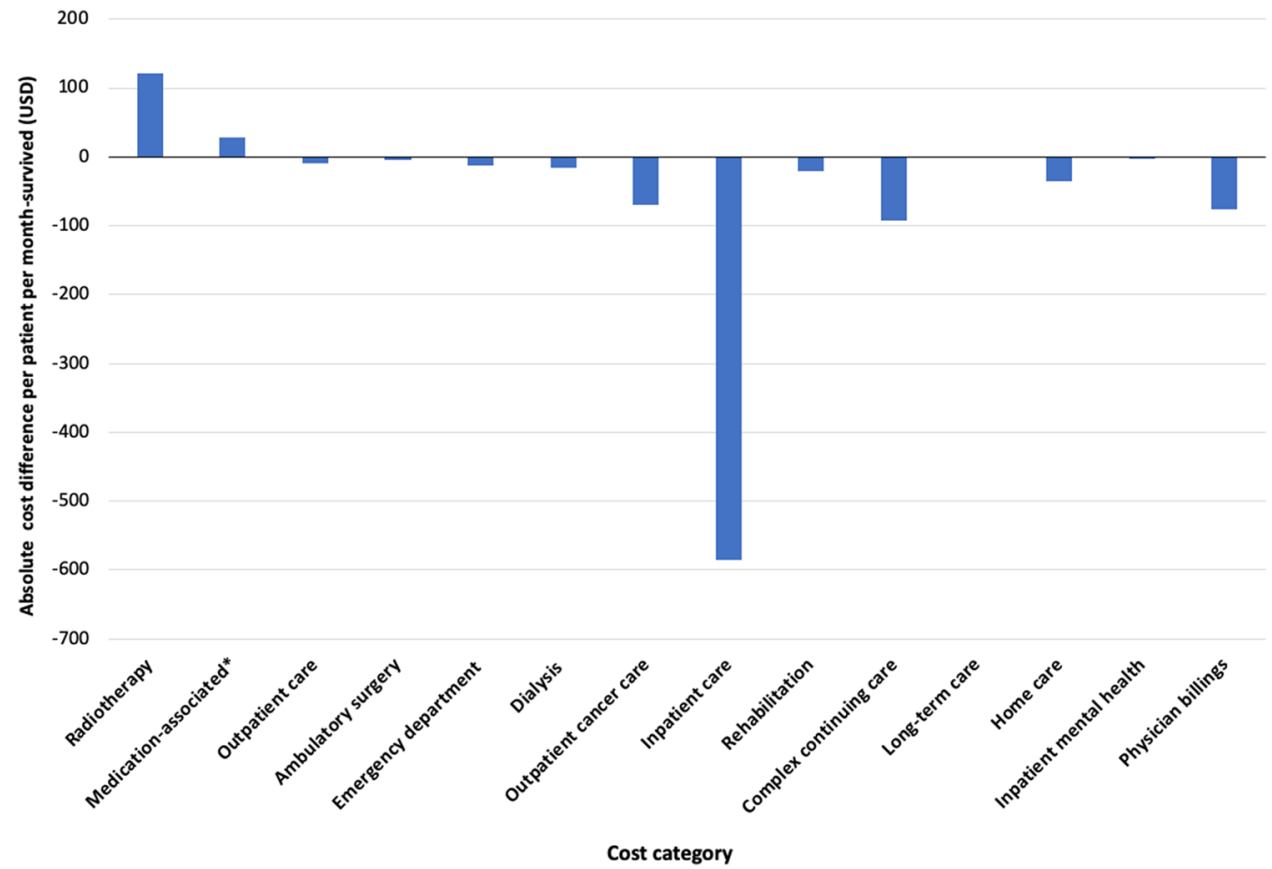

Fig. 2 Absolute difference in total costs/patient/monthsurvived between high- and low-volume providers, stratified by cost category. *including systemic therapy and supportive drugs benefit led to a significant reduction in cost per patient per month-survived. Specialized cancer care has been associated with higher rates of therapy and reduced costs for investigations and hospitalizations [12, 33, 43-45]. Population-based data previously revealed decreased cumulative hospital stays and use of homecare services with higher-volume physicians for metastatic gastric cancer, but did not relate those findings to patient outcomes or healthcare costs [47]. High use of inpatient care may be appropriate when facing sick or complex patients. However, it may not be appropriate when it can be avoided by providing therapy that improves symptom patterns and delays clinical deterioration while increasing 
Fig. 3 Incremental costs and survival benefit in a sensitivity analysis varying the cut-off to define high-volume providers. $N E$ northeast, intervention is cost-effective, $S E$ southeast, intervention is cost-dominant, $S W$ southwest, intervention is cost-effective, $N W$ northwest, intervention is cost-dominated

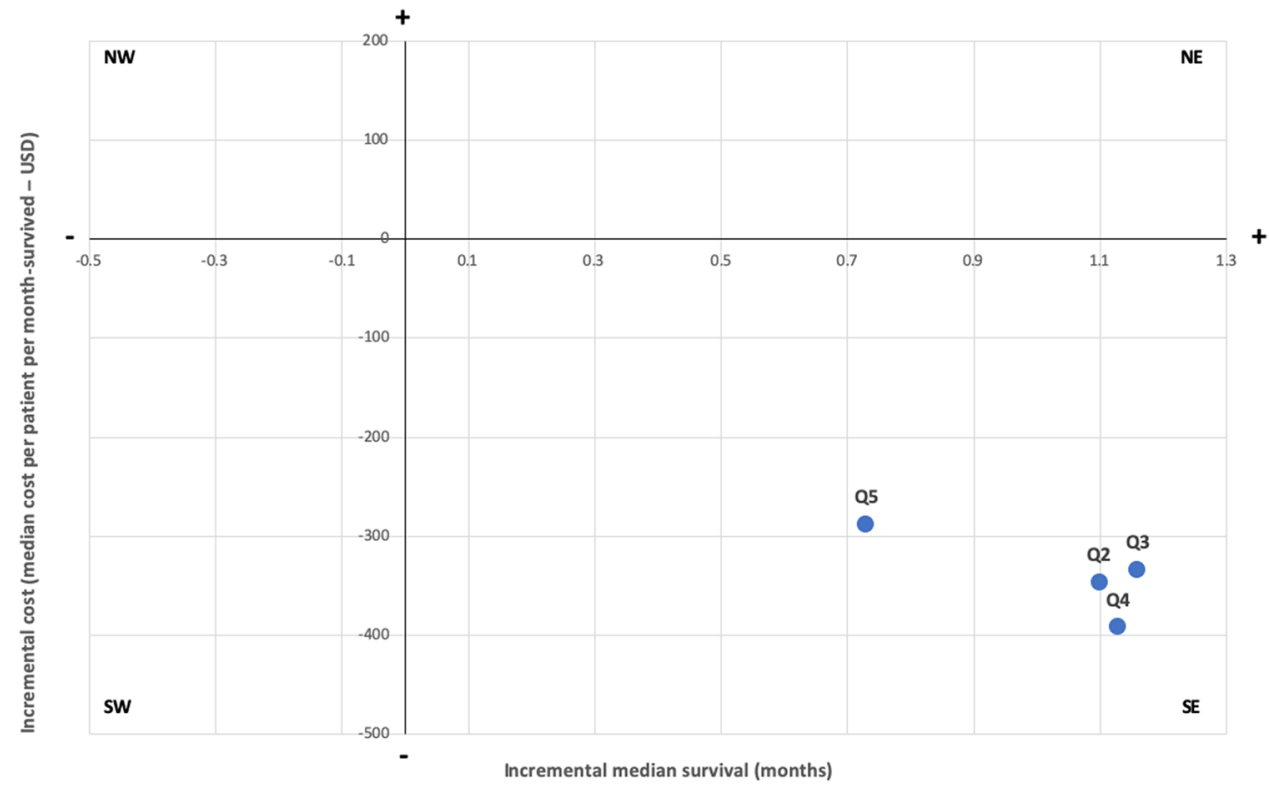

\begin{tabular}{|l|c|c|c|c|}
\hline Provider-volume quintile & Q2 & Q3 & Q4 & Q5 \\
\hline Number of patients per provider per year & 6 & 8 & 11 & 15 \\
\hline Number of patients treated by high-volume providers (\%) & $5,016(71.5 \%)$ & $3,735(53.3 \%)$ & $2,518(35.9 \%)$ & $1,302(18.6 \%)$ \\
\hline
\end{tabular}

survival, or by delivering integrated multi-disciplinary care that can prevent the need for hospitalization. In addition, less time in acute care settings is desirable from a patient perspective.

Managing rising costs is a constant preoccupation in current healthcare systems, whether through the allocation of governmental funds in public systems, or patterns of reimbursements and business models in private systems. In this study, we provide evidence that care by high-volume providers for non-curative EGC is a dominant strategy improving both healthcare expenses and survival. Such information is important for health systems and reimbursement bodies $[8,48]$. The dominant observation from this study could be explained by reduced unwarranted variation and inefficiencies in care delivery with high-volume providers resulting in scale economies and cost containment through better use of resources yielding longer survival [9, 49-51]. This should be taken into consideration when building policies and care pathways for effective, efficient, and quality cancer care.

There are some study limitations. Due to the retrospective and administrative nature of the work, the data used were not collected specifically to answer the research question. In particular, we lacked some information regarding disease characteristics, such as stage and tumor burden, and clinical trials data. The definition of high volume relied on quintiles, but other strategies have been used to define high volume [2]. The exact number defined herein may not perform the same in other jurisdictions. While the absolute cutoff may differ depending on the health system and practice setting, the observations regarding a high-volume practice concept remain valid. Finally, this study was conducted within the Canadian universally accessible and funded healthcare system, which can impact generalizability to other systems. However, prior work has shown that the attitudes of medical oncologists regarding the delivery of systemic therapy does not differ between the USA and Canada, despite differences in accessing and funding drugs [52]. Furthermore, the literature on surgical volume-outcome has yielded similar conclusions in various health systems across Canada, the USA, and Europe, supporting the generalizability of such findings [53-56]. Referral bias should be expected between low and high-volume providers, whereby more motivated patients may seek high-volume providers, or be referred from a low-volume to a high-volume provider, which we have accounted for as best as possible with multivariable modeling. Another issue is the variable length of followup in the cohort and between groups, with patients cared for by low-volume providers having shorter survival. We addressed this by reporting costs per patient per month-lived and conducting sensitivity analyses varying the time horizon to acquire costs.

This study offers a comprehensive analysis of healthcare costs with complete, reliable, and robust data available across the care continuum, within a universal healthcare system where insurance status does not confound access to and receipt of care. We were able to use real-life data for 
both costs and associated survival to directly relate costs to clinical benefits.

\section{Conclusion}

Care by high-volume providers for non-curative EGC is associated with superior survival and lower healthcare costs, indicating a dominant strategy, compared to care by low-volume providers. Lower inpatient acute care costs for high-volume providers was the main driver of the cost difference, despite higher costs for chemotherapy and radiotherapy provided by high-volume providers. Facilitating care by high-volume providers could provide an opportunity to improve outcomes for patients, while being cost-effective from a health systems perspective.

Acknowledgments This study was supported by ICES, which is funded by an annual grant from the Ontario Ministry of Health and Long-Term Care (MOHLTC). The opinions, results and conclusions reported in this paper are those of the authors and are independent from the funding sources. No endorsement by ICES or the Ontario MOHLTC is intended or should be inferred. Parts of this material are based on data and/or information compiled and provided by the Canadian Institute for Health Information (CIHI). However, the analyses, conclusions, opinions and statements expressed herein are those of the authors, and not necessarily those of CIHI. Parts of this material are based on data and information provided by Cancer Care Ontario (CCO). The opinions, results, view, and conclusions reported in this paper are those of the authors and do not necessarily reflect those of CCO. No endorsement by $\mathrm{CCO}$ is intended or should be inferred.

Author contribution Concept and study design: JH, NGC. Data acquisition and analysis: JH, NJLH, VZ, LED, VG, CCE, NM, NGC. Data interpretation: JH, NJLH, VZ, LED, VG, CCE, NM, NGC. Manuscript draft and critical revision: JH, NJLH, VZ, LED, VG, CCE, NM, NGC.

Funding This work was supported by an operating grant from the Canadian Institute of Health Research (CIHR-FRN \#154131).

\section{Compliance with ethical standards}

Conflict of interest $\mathrm{JH}$ has received speaking honoraria from Ipsen $\mathrm{Bi}$ opharmaceuticals Canada and Novartis Oncology. NGC received salary support from Cancer Care Ontario as the Clinical Lead for PatientReported Outcomes and Symptom Management.

\section{References}

1. Bilimoria KY, Bentrem DJ, Feinglass JM, et al. Directing surgical quality improvement initiatives: comparison of perioperative mortality and long-term survival for cancer surgery. J Clin Oncol. 2008;26(28):4626-33. https://doi.org/10.1200/JCO.2007.15.6356.

2. Halm EA, Lee C, Chassin MR. Is volume related to outcome in health care? A systematic review and methodologic critique of the literature. Ann Intern Med. 2002;137(6):511-20.

3. Birkmeyer JD, Stukel TA, Siewers AE, Goodney PP, Wennberg DE, Lucas FL. Surgeon volume and operative mortality in the
United States. N Engl J Med. 2003;349(22):2117-27. https:// doi.org/10.1056/NEJMsa035205.

4. Institute of Medicine (US) and National Research Council (US) National Cancer Policy Board, Hewitt M, Petitti D. Interpreting the volume-outcome relationship in the context of Cancer Care. 2001. doi: $10.17226 / 10160$.

5. Hallet J, Davis L, Mahar A, et al. Provider-volume associated with variable receipt of therapy and outcomes in non-curative pancreas adenocarcinoma: a population-based analysis. J Natl Comp Canc Netw. 2019; In Press.

6. Hallet J, Davis L, Mahar A, et al. Variation in receipt of therapy and survival with provider-volume for medical oncology in noncuratiev esophago-gastric cancer: a population-based analysis. Gastric Cancer. 2019; [EPub ahead of print] doi: 10.1007/ s10120-019-01012-z.

7. Bachmann MO, Alderson D, Peters TJ, et al. Influence of specialization on the management and outcome of patients with pancreatic cancer. Br J Surg. 2003;90(2):171-7. https://doi. org/10.1002/bjs.4028.

8. Birkmeyer JD, Skinner JS, Wennberg DE. Will volume-based referral strategies reduce costs or just save lives? Health Aff. 2002;21(5):234-41.

9. Chirikos TN, French DD, Luther SL. Potential economic effects of volume-outcome relationships in the treatment of three common cancers. Cancer Control. 2004;11(4):258-64. https://doi. org/10.1177/107327480401100409.

10. de Oliveira C, Bremner KE, Pataky R, et al. Understanding the costs of cancer care before and after diagnosis for the 21 most common cancers in Ontario: a population-based descriptive study. CMAJ Open. 2013;1(1):E1-E8. https://doi.org/10.9778/ cmajo.20120013.

11. Mahar AL, El-Sedfy A, Brar SS, Johnson A, Coburn N. Are we lacking economic evaluations in gastric cancer treatment? Pharmacoeconomics. 2015;33(2):83-7. https://doi.org/10.1007/ s40273-014-0215-1.

12. Thein H-H, Jembere N, Thavorn K, et al. Estimates and predictors of health care costs of esophageal adenocarcinoma: a population-based cohort study. BMC Cancer. 2018;18(1):694. https://doi.org/10.1186/s12885-018-4620-2.

13. Global Burden of Disease Cancer Collaboration, Fitzmaurice C, Akinyemiju TF, et al. Global, Regional, and National Cancer Incidence, Mortality, Years of Life Lost, Years Lived With Disability, and Disability-Adjusted Life-Years for 29 Cancer Groups, 1990 to 2016: A Systematic Analysis for the Global Burden of Disease Study. JAMA Oncol. 2018;4(11):1553-1568. doi: 10.1001/jamaoncol.2018.2706.

14. Government of Canada. Canada Health Act - Health Care System - Health Canada. https://www.hc-sc.gc.ca/hcs-sss/mediassur/cha-lcs/index-eng.php.

15. Husereau D, Drummond M, Petrou S, et al. ISPOR Task Force Report: Consolidated Health Economic Evaluation Reporting Standards (CHEERS) - Explanation and Elaboration: A Report of the ISPOR Health Economic Evaluation Publication Guidelines Good Reporting Practices Task Force. Value in Health. 2013;16(2):231-50. https://doi.org/10.1016/j.jval.2013.02.002.

16. Benchimol EI, Smeeth L, Guttmann A, et al. The REporting of studies Conducted using Observational Routinelycollected health Data (RECORD) Statement. PLoS Med. 2015;12(10):e1001885-e10019221001922. https://doi. org/10.1371/journal.pmed.1001885.

17. Hallet J, Davis LE, Mahar AL, et al. Variation in receipt of therapy and survival with provider volume for medical oncology in non-curative esophago-gastric cancer: a population-based analysis. Gastric Cancer. 2019;26(Suppl 1):4626-710. https:// doi.org/10.1007/s10120-019-01012-z. 
18. Dixon M, Mahar AL, Helyer LK, Vasilevska-Ristovska J, Law C, Coburn NG. Prognostic factors in metastatic gastric cancer: results of a population-based, retrospective cohort study in Ontario. Gastric Cancer. 2015;19(1):1-10. https://doi. org/10.1007/s10120-014-0442-3.

19. Wodchis WP, Naglie G, Teare GF. Validating diagnostic information on the minimum data set in Ontario Hospital-based long-term care. Med Care. 2008;46(8):882-7. https://doi. org/10.1097/MLR.0b013e3181789471.

20. Look Hong NJ, Cheng SY, Wright FC, Petrella TM, Earle CC, Mittmann N. Resource utilization and disaggregated cost analysis for initial treatment of melanoma. J Cancer Policy. 2018;16:63-9. https://doi.org/10.1016/j.jcpo.2018.04.006.

21. Mittmann N, Earle CC, Cheng SY, et al. Population-based study to determine the health system costs of using the 21-gene assay. J Clin Oncol. 2018;36(3):238-43. https://doi.org/10.1200/ JCO.2017.74.2577.

22. Pink GH, Bolley HB. Physicians in health care management: 4 . Case Mix Groups and Resource Intensity Weights: physicians and hospital funding. CMAJ. 1994;150(8):1255-1261.

23. Drug Formulary. Cancer Care Ontario. https://www.cancercare ontario.ca/en/drugformulary/regimens. Accessed May 2019.

24. Karlj B. Measuring "rurality" for purposes of health-care planning: an empirical measure for Ontario. Ont Med Rev. 2009; October:33-52.

25. Alter DA, Naylor CD, Austin P, Tu JV. Effects of socioeconomic status on access to invasive cardiac procedures and on mortality after acute myocardial infarction. N Engl J Med. 1999;341(18):1359-67. https://doi.org/10.1056/NEJM199910 283411806.

26. Wilkins R. Use of postal codes and addresses in the analysis of health data. Health Rep. 1993;5(2):157-77.

27. Elixhauser A, Steiner C, Harris DR, Coffey RM. Comorbidity measures for use with administrative data. Med Care. 1998;36(1):8-27.

28. Gutacker N, Bloor K, Cookson R. Comparing the performance of the Charlson/Deyo and Elixhauser comorbidity measures across five European countries and three conditions. Eur J Public Health. 2015;25(suppl_1):15-20. doi: 10.1093/eurpub/ cku221.

29. Nam RK, Cheung P, Herschorn S, et al. Incidence of complications other than urinary incontinence or erectile dysfunction after radical prostatectomy or radiotherapy for prostate cancer: a population-based cohort study. Lancet Oncol. 2014;15(2):223-31. https://doi.org/10.1016/S1470-2045(13)70606-5.

30. Rabeneck L, Paszat LF, Rothwell DM, He J. Temporal trends in new diagnoses of colorectal cancer with obstruction, perforation, or emergency admission in Ontario: 1993-2001. Am J Gastroenterol. 2005;100(3):672-6. https://doi.org/10.111 1/j.1572-0241.2005.41228.x.

31. Kagedan DJ, Abraham L, Goyert N, et al. Beyond the dollar: Influence of sociodemographic marginalization on surgical resection, adjuvant therapy, and survival in patients with pancreatic cancer. Cancer. 2016;122(20):3175-82. https://doi.org/10.1002/ cncr.30148.

32. Kaplan EL, Meier P. Nonparametric estimation from incomplete observations. J Am Stat Assoc. 2012;6(282):128-32.

33. Lee JA, Park JH, Lee EJ, Kim SY, Kim Y, Lee S-I. High-quality, low-cost gastrectomy care at high-volume hospitals: results from a population-based study in South Korea. Arch Surg. 2011;146(8):930-6. https://doi.org/10.1001/archsurg.2011.81.

34. Ireland $\mathrm{C}$, Wiedower $\mathrm{E}$, Mirza $\mathrm{M}$, et al. Impact of provider volume on outcomes of patients with Hodgkin lymphoma. World J Oncol. 2018;9(2):46-9. https://doi.org/10.14740/wjon1093w.

35. Huntington SF, Hoag JR, Zhu W, et al. Oncologist volume and outcomes in older adults diagnosed with diffuse large $b$ cell lymphoma. Cancer. 2018;64(21):786-4220. https://doi. org/10.1002/cncr.31688.

36. Go RS, Bartley AC, Crowson CS, et al. Association between treatment facility volume and mortality of patients with multiple myeloma. J Clin Oncol. 2017;35(6):598-604. https://doi.org/10.1200/ JCO.2016.68.3805.

37. Go RS, Al-Hamadani M, Shah ND, Crowson CS, Holton SJ, Habermann EB. Influence of the treatment facility volume on the survival of patients with non-Hodgkin lymphoma. Cancer. 2016;122(16):2552-9. https://doi.org/10.1002/cncr.30038.

38. Shanafelt TD, Kay NE, Rabe KG, et al. Hematologist/oncologist disease-specific expertise and survival: lessons from chronic lymphocytic leukemia (CLL)/small lymphocytic lymphoma (SLL). Cancer. 2012;118(7):1827-37. https://doi.org/10.1002/cncr.26474

39. Shiroiwa T, Fukuda T, Shimozuma K. Cost-effectiveness analysis of trastuzumab to treat HER2-positive advanced gastric cancer based on the randomised ToGA trial. Br J Cancer. 2011;105(9):1273-8. https://doi.org/10.1038/bjc.2011.390.

40. Peng J, Tan C, Zeng X, Liu S. Cost-effectiveness analysis of capecitabine monotherapy versus capecitabine plus oxaliplatin in elderly patients with advanced gastric cancer. De Mello RA, ed. PLoS ONE. 2018;13(6):e0199553. doi: 10.1371/journal. pone.0199553.

41. Wang SJ, Fuller CD, Choi M, Thomas CR. A cost-effectiveness analysis of adjuvant chemoradiotherapy for resected gastric cancer. Gastrointest Cancer Res. 2008;2(2):57-63.

42. Lam SW, Wai M, Lau JE, McNamara M, Earl M, Udeh B. Costeffectiveness analysis of second-line chemotherapy agents for advanced gastric cancer. Pharmacotherapy. 2017;37(1):94-103. https://doi.org/10.1002/phar.1870.

43. Harmon JW, Tang DG, Gordon TA, et al. Hospital volume can serve as a surrogate for surgeon volume for achieving excellent outcomes in colorectal resection. Ann Surg. 1999;230(3):404-11 discussion 411-3.

44. Hess LM, Michael D, Mytelka DS, Beyrer J, Liepa AM, Nicol S. Chemotherapy treatment patterns, costs, and outcomes of patients with gastric cancer in the United States: a retrospective analysis of electronic medical record (EMR) and administrative claims data. Gastric Cancer. 2016;19(2):607-15. https://doi.org/10.1007/s1012 0-015-0486-Z

45. Rea JD, Lu KC, Diggs BS, Cone MM, Hardiman KM, Herzig DO. Specialized practice reduces inpatient mortality, length of stay, and cost in the care of colorectal patients. Dis Colon Rectum. 2011;54(7):780-6. https://doi.org/10.1007/DCR.0b013e3182 $1484 \mathrm{~d} 2$.

46. Bachmann M, Peters T, Harvey I. Costs and concentration of cancer care: evidence for pancreatic, oesophageal and gastric cancers in National Health Service hospitals. J Health Serv Res Policy. 2003;8(2):75-82. https://doi.org/10.1258/135581903321466030.

47. Mahar AL, Coburn NG, Viola R, Johnson AP. Predictors of hospital stay and home care services use: a population-based, retrospective cohort study in stage IV gastric cancer. Palliat Med. 2015;29(2):147-56. https://doi.org/10.1177/0269216314554325.

48. Shahian DM, Normand S-LT. The volume-outcome relationship: from Luft to Leapfrog. ATS. 2003;75(3):1048-1058.

49. Mercuri M, Gafni A. Medical practice variations: what the literature tells us (or does not) about what are warranted and unwarranted variations. J Eval Clin Pract. 2011;17(4):671-7. https://doi. org/10.1111/j.1365-2753.2011.01689.x.

50. Wennberg JE. Unwarranted variations in healthcare delivery: implications for academic medical centres. BMJ. 2002;325(7370):961-4.

51. Goodman DC. Unwarranted variation in pediatric medical care. Pediatr Clin N Am. 2009;56(4):745-55. https://doi.org/10.1016/j. pcl.2009.05.007. 
52. Berry SR, Bell CM, Ubel PA, et al. Continental divide? The attitudes of US and Canadian oncologists on the costs, cost-effectiveness, and health policies associated with new cancer drugs. J Clin Oncol. 2010;28(27):4149-53. https://doi.org/10.1200/ JCO.2010.29.1625.

53. Birkmeyer JD, Siewers AE, Marth NJ, Goodman DC. Regionalization of high-risk surgery and implications for patient travel times. JAMA. 2003;290(20):2703-8. https://doi.org/10.1001/ jama.290.20.2703.

54. Simunovic M, Urbach D, Major D, et al. Assessing the volumeoutcome hypothesis and region-level quality improvement interventions: pancreas cancer surgery in two Canadian Provinces. Ann Surg Oncol. 2010;17(10):2537-44. https://doi.org/10.1245/s1043 4-010-1114-0.

55. Dikken JL, Dassen AE, Lemmens VEP, et al. Effect of hospital volume on postoperative mortality and survival after oesophageal and gastric cancer surgery in the Netherlands between 1989 and 2009. Eur J Cancer. 2012;48(7):1004-133. https://doi. org/10.1016/j.ejca.2012.02.064.

56. Fischer C, Lingsma H, Klazinga N, et al. Volume-outcome revisited: the effect of hospital and surgeon volumes on multiple outcome measures in oesophago-gastric cancer surgery. Smith ZA, ed. PLoS One. 2017;12(10):e0183955. doi:10.1371/journal. pone. 0183955 .

Publisher's Note Springer Nature remains neutral with regard to jurisdictional claims in published maps and institutional affiliations. 